\title{
Distributional Patterns of ABO Blood Grouping and Rhesus Factor: Retrospective Cross-Sectional Study in Somali Regional Blood Bank
}

\author{
Abibakar Sheikaden Ismail \\ Public Health Department, Jigjiga University, Jiggjiga, Ethiopia \\ Email address: \\ isdalmar@gmail.com, dalmar25@yahoo.com

\section{To cite this article:} \\ Abibakar Sheikaden Ismail. Distributional Patterns of ABO Blood Grouping and Rhesus Factor: Retrospective Cross-Sectional Study in \\ Somali Regional Blood Bank. American Journal of Laboratory Medicine. Vol. 4, No. 2, 2019, pp. 48-52. doi: 10.11648/j.ajlm.20190402.15
}

Received: March 4, 2019; Accepted: April 11, 2019; Published: May 31, 2019

\begin{abstract}
Blood is the most important body fluid. It is responsible for the transportation of the most critical substance, oxygen. The human red blood cell membrane contains different types of antigens, called agglutinogens. These antigens are capable of inducing specific immune response which in turn results in the production of antibodies. From the thirty blood group system genes already identified, the most important blood group systems are the ABO and Rh. Frequency of the four main $\mathrm{ABO}$ blood groups vary throughout the world mainly due to differences in geographical location and ethnicity. The aim of this study was to describe the distributional patterns of ABO blood grouping and Rh factor in Somali Regional State. A retrospective cross-sectional study was conducted in the blood bank from January 1 to February 10, 2019. Sample of three years (2015 to 2017) data was collected purposively. Data collectors were oriented prior to data collection and the study tool was pre-tested for corrections if any. Data processing and descriptive data analysis was undertaken by employing Microsoft Excel 2013 and SPSS 20. Ethical clearance letter was obtained from the Somali Regional Health Bureau and it was presented to the study facility. Blood group O has the highest frequency, 2,310 (50.10\%) followed by blood group A, 1,366 (29.60\%); B $702(15.20 \%)$ and $\mathrm{AB} 236(5.10 \%)$. The overall Rhesus factor positivity and negativity was 4,410 (95.6\%) and $204(4.4 \%)$ respectively. Blood group O is the most frequent blood type among blood donors in Somali region. Then, followed by A, B, and $\mathrm{AB}$ blood types. Absolute majority of blood donors in the region have Rh positive gene in the surface of their RBCs. Contact details of blood donors with rare blood types should be retained for tracking in cases of emergency blood donation requests. Concerned bodies at different levels should use findings from this study for planning and blood bank management.
\end{abstract}

Keywords: Distributional Patterns, ABO Blood Grouping, Rh Factor, Somali Region

\section{Introduction}

Blood is the most important body fluid. It is responsible for the transportation/circulation of the most critical substance, oxygen and other important nutrients, enzymes and hormones all across the body. The human red blood cell (RBC) membrane contains different types of polysaccharide antigens, called agglutinogens [1]. The antigenic substances are capable of inducing a specific immune response and that specific response results in the production of cells termed as antibodies [2]. These antigens are genetically controlled and are inherited in early fetal life by Mendelian manner and remain the same till death [3]. International Society of Blood Transfusion has identified 30 blood group system genes.
The most important blood group systems are $\mathrm{ABO}$ (A, B $\& \mathrm{O}$ ) and Rhesus (Rh) [4]. This is mainly due to the vast majority of the population carrying pre-formed $\mathrm{ABO}$ antibodies; this is the only blood group system where if you lack the antigen you will make the corresponding antibody without deliberate immunization [5]. The genes of ABO \& $\mathrm{Rh}$ (D) are located on chromosome $9 \& 1$ respectively. The ABO blood group system was discovered by Karl Landsteiner in 1901. It was the first blood group system to be discovered. Landsteiner had mixed the sera and red cells from his co-workers and discovered that they reacted in different ways. He named three groups A, B and O. In 1902 Decastello and Sturli discovered the additional $\mathrm{AB}$ phenotype [5]. The ABO blood group is determined by the 
presence of $\mathrm{A}$ and $\mathrm{B}$ antigens on the surface of the red blood cells, and of anti -A or anti -B antibodies in the serum. Hence, the red blood cells of blood type A possess antigen A and the serum contains anti $-\mathrm{B}$ antibody. Similarly, blood type $\mathrm{B}$ has antigen $\mathrm{B}$ and anti - $\mathrm{A}$ antibody. Blood type $\mathrm{AB}$ contains both $\mathrm{A}$ and $\mathrm{B}$ antigens but no antibodies. Blood type $\mathrm{O}$ has no antigens but it contains both anti - A and anti - B antibodies. Anti -A and anti -B antibodies are usually IgM type (Immunoglobulin $\mathrm{M}$ ), and not present in newborns, but appear in the first year of life [6].

The $\mathrm{Rh}$ blood groups are so named because one of the eight $\mathrm{Rh}$ antigens (agglutinogen $\mathrm{D}$ ), was originally identified in Rhesus monkeys. Later the same antigen was discovered in human beings. Most people are $\mathrm{Rh}+$ ( $\mathrm{Rh}$ positive), meaning that their RBCs carry the Rh antigen [5]. Rhesus antigens are most immunogenic. From the $49 \mathrm{Rh}$ antigens identified, expression of D antigen is the most crucial.

It's very pivotal to determine the blood group of both donor and recipient before any blood transfusion [7]. The health and safety of both patients and donors is central in blood transfusions. This requires advanced production methods, strict procedures, stringent quality requirements and checks, regulations and monitoring during the administration. Every donation is tested, thereby minimizing the risk of blood-transferable infections through blood components [8]. If we were to randomly transfuse red cells to a group of people without $\mathrm{ABO}$ grouping either the donors or the recipients there is a high probability that some would receive ABO incompatible blood and potentially undergo an acute haemolytic transfusion reaction. As such it is of paramount importance that both the blood donor and blood component recipient are $\mathrm{ABO}$ grouped correctly and compatible blood components are transfused [5]. Since rhesus antigens are very immunogenic, its typing is also very crucial for safer blood transfusion. When D negative individuals encounter the D antigen they produce anti $\mathrm{D}$ which causes hemolytic transfusion reaction, or hemolytic disease of the newborn. For this reason, the status of Rh typing is determined in blood donors, recipients who receive blood transfusion, and in pregnant ladies [9].

Frequency of the four main $\mathrm{ABO}$ blood groups varies in the population throughout the world mainly due to differences in geographical location and ethnicity. In Caucasians in the United States, the distribution is $47 \%$ for group O, 41\% for group A, 9\% for group B and 3\% for group AB. Among the African Americans, the distribution is $46 \%$ for group O, 27\% for group A, 20\% for group B and 7\% for group $\mathrm{AB}$. In the Orientals, the distribution of blood group is $36 \%$ for group O, $28 \%$ for group A, $23 \%$ for group B and $13 \%$ for group $\mathrm{AB}[10]$.

Ethiopia is a country with a great geographical as well as ethnic diversities. There are about 80 different ethnic groups in the country. Somali Regional State is one of the nine administrative regions in Ethiopia. The region is inhibited by ethnic Somali people whose pastoralist life style is still largely dominant. There is no known country wide studies on the distributional patterns of $\mathrm{ABO}$ blood grouping and $\mathrm{Rh}$ typing except some studies in the highlands of the country. In this studies, the frequency of blood groups was $\mathrm{O}, \mathrm{A}, \mathrm{B}$ and $\mathrm{AB}$ respectively. Hence, the aim of this study is to describe the distributional patterns of ABO blood grouping and $\mathrm{Rh}$ factor in Somali Region for better blood transfusion services and blood bank management.

\section{Materials and Methods}

\subsection{Study Setting}

The study was undertaken in Somali Regional Blood Bank in the capital Jigjiga, eastern Ethiopia. This blood bank is the largest and only the very existing one in the region except emergency mini-blood banks in some health facilities. Therefore, it provides day to day services to needy individuals that are from all over the elven zones of this region and perhaps, individuals from other regions of Ethiopia. As per the last Ethiopian housing and population census in 2007, the regional population can now be projected as $5,824,161$ with $2.6 \%$ annual growth rate [11]. Since, the blood bank is in the regional capital, blood donors and subsequent recipients were expected to be good representatives for the region wide population.

\subsection{Study Design and Period}

A retrospective cross-sectional study was conducted in Somali Regional State Blood Bank from January 1 to February 10, 2019.

\subsection{Sample Size and Sampling Procedure}

All blood donors (volunteers \& donors for replacement) who had donated blood and whose blood had passed transfusion legibility screening process from 2015 to 2017 were included in the study. Data of these three consecutive years was taken purposively because complete data were available unlike other years with incomplete data based on prior reviews of registration log books.

\subsection{Data Collection and Quality Control}

Data were collected using checklist with separate blood group categories. Frequency of each blood type in each year was recorded in an ordinary tally style with five records at once. Data collectors were oriented on how to collect data retrospectively from the available registers. Study tool was pre-tested before actual data collection commencement for any corrections or rearrangements.

\subsection{Data Processing and Analysis}

Data processing (entry, cleaning, editing, coding) was undertaken by using Microsoft Excel 2013. Then, data were exported to Statistical Software for Social Science (SPSS) version 20. Subsequent analysis of data was done by employing both Excel Spread Sheet and SPSS. Descriptive analysis of the distributional patterns of blood grouping and $\mathrm{Rh}$ factor was performed and depicted in frequency 
distribution tables, graphs or charts.

\subsection{Ethical Clearance}

Ethical clearance was obtained from the Somali Regional Health Bureau (SRHB). Then, this was be presented to the blood bank managing body to gain further permissions for data collection. To maintain confidentiality of information filled in checklists, basic identifiers of blood donors were not used. Rather, frequency of donor's blood types in each year was tallied and data were secured in a save area.

\section{Results}

Data of 4,614 blood donors who had donated blood from 2015 to 2017 was analyzed. Blood group $\mathrm{O}$ has the highest frequency, 2,310 (50.10\%) followed by blood group A, 1,366 (29.60\%); B 702 (15.20\%) and AB 236 (5.10\%). The overall Rhesus factor positivity and negativity was 4,410 (95.6\%) and 204 (4.4\%) respectively.

Table 1. Frequency of ABO blood types and Rhesus factor from 2015 to 2017, Somali Region, Ethiopia.

\begin{tabular}{lllll}
\hline \multirow{2}{*}{ Blood Type } & Rh Factor (D) & & Blood Type Frequency & Percentage \\
\cline { 2 - 5 } & Positive & Negative & 1,366 & $29.60 \%$ \\
A & $1,310(95.9 \%)$ & $56(4.1 \%)$ & 702 & $15.20 \%$ \\
B & $665(94.7 \%)$ & $37(5.3 \%)$ & 236 & $5.10 \%$ \\
AB & $225(95.3 \%)$ & $11(4.7 \%)$ & 2,310 & $50.10 \%$ \\
O & $2,210(95.7 \%)$ & $100(4.3 \%)$ & 4,614 & $100.00 \%$ \\
Total ABO Blood Collected (n) & & & & \\
\hline
\end{tabular}

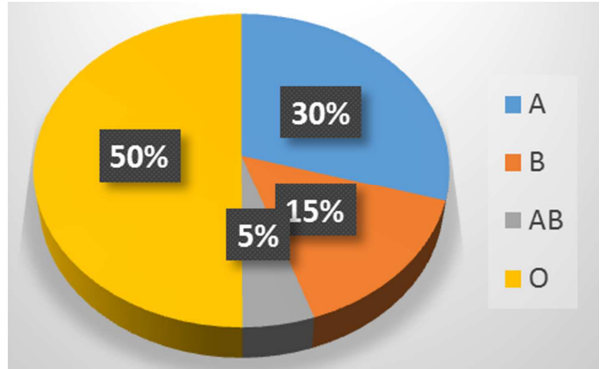

Figure 1. Blood type distribution from 2015 to 2017, Somali Region, Ethiopia.

Three years patterns/trends of blood group types and the $\mathrm{Rh}$ factor was plotted in figure 2. The highest frequency of $\mathrm{O}, \mathrm{A}$ and B blood groups was recorded in 2015 and 2017 whereas, $\mathrm{AB}$ blood type frequency was higher in 2017 and 2015. There was no registered $\mathrm{AB}^{-}$blood type in 2016 (figure 2).

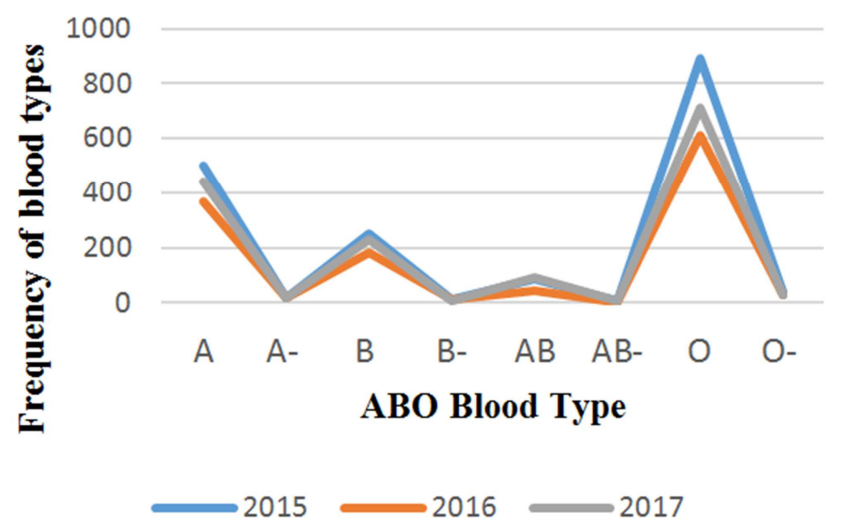

Figure 2. Patterns of ABO blood grouping and Rh factor from 2015 to 2017, Somali Region, Ethiopia.

\section{Discussion}

Evidence based information on the distribution of blood types and $\mathrm{Rh}$ factor is very pivotal for routine blood donor selection, overall blood bank management and planning. Most importantly, concrete knowledge ABO blood groups and $\mathrm{Rh}$ factor is of crucial importance to track blood donor's of rare blood types ( $\mathrm{Rh}$ negative individuals) and their subsequent recruitment for vital blood donations to their needy counterpart recipients.

In this study, the most common blood type was $\mathrm{O} ; 2,310$ (50.10\%), followed by A; 1,366 (29.60\%), B; 702 (15.20\%) and $\mathrm{AB} ; 236(5.10 \%)$ blood types respectively. And the overall $\mathrm{Rh}$ positivity and negativity was $4,410(95.6 \%)$ and $204(4.4 \%)$. In this case, the frequency distribution of $\mathrm{O}$ blood type in Somali region is higher than that reported by other studies conducted in Ethiopia or elsewhere in the world. This can be mainly due to ethnicity or geographical differences among study populations and or study sample size variations.

Similarly, in studies from Australia, Britain and USA, blood group ' $\mathrm{O}$ ' and ' $\mathrm{A}$ ' were the commonest followed by $\mathrm{B}$ and $A B$ [12 - 14]. In African continent, the most common phenotypic frequency order of blood group is; $\mathrm{O}>\mathrm{A}>\mathrm{B}>\mathrm{AB}$ [15]. In Nigeria, different studies have also reported similar findings with blood group $\mathrm{O}$ having the highest frequency, followed by $\mathrm{A}$, then $\mathrm{B}$ while $\mathrm{AB}$ has the lowest frequency [16 - 18]. Moreover, a study from Dilla University, Southern Ethiopia, found that the most prevalent blood group was type $\mathrm{O}(44.49 \%)$ followed by A $(26.32 \%)$, B (26.32\%), and AB $(2.87 \%)$ [19]. And in a study conducted in Tigray region, northern Ethiopia, the most predominant blood phenotype was O $(41.5 \%)$ followed by phenotype A (28\%), Phenotype $\mathrm{B}(25 \%)$ and phenotype $\mathrm{AB}(5.5 \%)$. Additionally, the $\mathrm{Rh}$ positivity and negativity rate in this study was $91.2 \%$ and $8.8 \%$ respectively [20].

Differently, a study conducted in Jodhpur city, Indian State of Rajasthan, revealed that the commonest $\mathrm{ABO}$ blood group was B (36.4\%), followed by $\mathrm{O}(31.7 \%)$, A (22.2\%) and AB (9.4\%) respectively. $\mathrm{Rh}$ Positive was $91.75 \%$ and $\mathrm{Rh}$ negative were $8.25 \%$ [21]. In another study conducted in 
Bangladesh, distribution of blood group $\mathrm{O}$ was the highest (34.2\%), but differently followed by blood group B (32.2\%), A (24\%) and $\mathrm{AB}(9.6 \%)$. In this study, percentage of Rhesus positive blood types was $96 \%$ and while Rhesus negative was $4 \%[22]$.

\section{Limitations of the Study}

As a retrospective survey, secondary data was collected and then, analyzed. In such cases, documents may not be very representative for the wider population or may lack key information about certain groups (marginalized groups). Moreover, a possible inter-gender blood group difference was not studied in this study. Hence, it can't clarify if ABO blood group frequency distribution differences exist between male and female blood donors.

\section{Conclusion and Recommendation}

Blood group $\mathrm{O}$ is the most frequent blood type among blood donors in Somali region. Then, followed by A, B, and $\mathrm{AB}$ blood types respectively. Absolute majority of blood donors in the region have $\mathrm{Rh}$ positive gene in the surface of their RBCs. Patterns of ABO blood groups and Rh factor throughout the three years depicts similar follow of blood type frequency but differences in the magnitude of yearly blood donors.

Somali regional blood bank services should retain contact details of individuals with rare blood types like $\mathrm{AB}$ and $\mathrm{Rh}$ negative because this can be crucial tracking means at times of emergency blood donation requests for such individuals. Furthermore, the SRHB in collaboration with the regional bank should use findings of this study for planning and $\mathrm{ABO}$ blood stock and distribution management.

\section{Acronyms}

ABO: A, B, \& O Blood types; HDN: Hemolytic Disease of the New Born; Ig $^{\mathrm{M}}$ : Immunoglobulin M; RBC: Red Blood Cell; SRHB: Somali Regional Health Bureau; SPSS: Statistical Page for Social Science.

\section{Acknowledgements}

I would like to extend my gratitude to Somali Regional Health Bureau Deputy Head, Mr. Abdiwahab Sheik Mohamed for his facilitations during ethical clearance for the study and his subsequent signature of the permission letter to the study facility.

I would also like express my in depth appreciation and sincerity to the regional blood bank authority and data collectors for their humble cooperation and tireless work respectively.

\section{References}

[1] Ganong WF. Review of Medical Physiology. $17^{\text {th }}$ edition. Prentice Hall International Inc. London: 1995, pp. 487-9.
[2] Hoffbrand AV. Post Graduate Haematology, $2^{\text {nd }}$ edition. Heinmann Professional Publishing Ltd., London: 1981, pp. 270-350.

[3] Firkin F, Chesterman C, Penington D, Rush B. Blood groups; blood transfusion; acquired immune deficiency syndrome. In: De Gruchy's clinical haematology in medical practice. 5th ed. Wiley-Blackwell; 1989: 475-96.

[4] International Society of Blood Transfusion (ISBT). Table of blood group systems. Oct 2008. Available at: http://www.isbtweb.org/fileadmin/user upload/files 2015/red\%20cells/general\%20intro\% $\% 20 \mathrm{WP} /$ Table $\% 20$ blood $\%$ 20group\%20systems\%20v4.0\%20141125.pdf. Accessed on 13.06.2016.

[5] Geof Daniels. Chapter 6. The ABO Blood Group System.

[6] Eiji Hosoi. Biological and clinical aspects of ABO blood group system. The Journal of Medical Investigation. Vol. 55 2008.

[7] Z. H. Al-Zubaydi. Blood Groups and Transfusions. Medical Physiology: Lecture 7, 1-4.

[8] CBO. Blood Transfusion Guideline: National Users' Board Sanquin Blood Supply. Netherlands, 2011.

[9] Bethesda DL. Blood Groups and Red Cell Antigens. In: The $\mathrm{Rh}$ blood group. USA: National Center for Biotechnology Information. 2005; p.1-6.

[10] Pramanik T and Pramanik S. "Distribution of $A B O$ and $R h$ blood groups in Nepalese students: a report”. The Eastern Mediterranean Health Journal. 6.1 (2000): 156-158.

[11] Federal Democratic Republic of Ethiopia Population Census Commission. Summary and Statistical Report of the 2007 Population and Housing Census Results. Addis Ababa, December 2008.

[12] Australian Red Cross Blood Service: About blood (2013). Available from: http://www.donateblood.com.au/about-blood/types.

[13] Frances TF (2002). Blood groups (ABO groups). Common Laboratory and Diagnostic Tests. 3rd ed. USA: Lippincott, Williams \& Wilkins, Philadelphia pp. 19-25.

[14] Mourant AE, Kopec AC, Domaniewska-Sobczak K (1976). The distribution of the human blood groups and other polymorphisms. 2nd ed. London: Oxford University Press $p$ 1.005 .

[15] Rashaduz Zaman, Mohammad Parvez, Md. Jakaria and Mohammed Abu Sayeed. Study of ABO and Rh-D blood group among the common people of Chittagong city corporation area of Bangladesh. Journal of Public Health and Epidemiology. Vol. 7(9), pp. 305-310, September 2015 DOI: 10.5897/JPHE2015.0727.

[16] Nwuche CA and Ejele OA. "ABO and rhesus antigens in a cosmopolitan Nigeria population". Nigerian Journal of Medicine. 13.3 (2004): 263-266.

[17] Falusi AG., et al. "Distribution of $\mathrm{ABO}$ and $\mathrm{RH}$ genes in Nigeria". African Journal of Medicine and Medical Sciences. 29.1 (2000): 23-26.

[18] Enosolease ME and Bazuaye GN. "Distribution of ABO and Rh-D blood groups in the Benin area of Niger-Delta: implication for regional blood transfusion". Asian Journal of Transfusion Science. 2.1 (2008): 3-5. 
[19] Fekadu Alemu Atire. Distribution of ABO and Rh Blood Groups Among Students of Some Ethnic Groups at Dilla University, Ethiopia. International Journal of Genetics and Genomics; 3(1), 2015: 8-19. doi: 10.11648/j.ijgg.20150301.12.

[20] Megbaru Alemu, Guesh Abrha, Gessessew Bugssa, Kiros Tedla. Frequency of $\mathrm{ABO}$ and $\mathrm{Rh}$ (D) Blood Groups and Hemoglobin Threshold among Pregnant Women in Family Guidance Association, Mekelle Model Clinic, North Ethiopia. International Journal of Pharma Sciences and Research (IJPSR). Vol. 5, 12 Dec 2014.
[21] Behra Rajshree, Joshi Yogi Raj. Distribution of ABO Blood Group and Rh (D) Factor in Western Rajasthan, Jodhpur, India. National Journal of Medical Research. Volume 3 (1); Jan - March 2013.

[22] Shamima Nasrin Shadia, Md Rabiul Islam and Moazzem Hossain. ABO and Rhesus Blood Group Distribution among Garment Factory Workers, Bangladesh. Acta Scientific Microbiology (ISSN: 2581-3226). Vol. 1 (7), July 2018. 